\section{Commentary: Time to open Pandora's box: Assessing true costs in cardiac surgery}

\author{
Alexander A. Brescia, MD, MSc, and \\ Gorav Ailawadi, MD, MBA
}

In a statewide retrospective study, Salenger and colleagues ${ }^{1}$ linked clinical data from the Society of Thoracic Surgeons (STS) Adult Cardiac Surgery Database (ACSD) to hospital charge data from the Maryland Health Care Commission for coronary artery bypass grafting $(\mathrm{CABG})$ procedures at 9 Maryland hospitals to identify modifiable factors associated with interhospital variability in hospital charges. From these data, the authors concluded that by targeting the factors associated with greater hospital charges, hospitals "can realize cost savings while improving quality of care" for patients undergoing CABG. ${ }^{1}$ The authors should be commended for leveraging a statewide database to link hospital charge to clinical data. Their main conclusion was that patients with longer operations, longer length of stay, and more postoperative morbidity have, not unexpectedly, greater hospital charges. However, assessing true hospital costs remains Pandora's box, as these findings only reflect fee-for-service hospital billing structures. Moreover, hospital billing practices reflecting charges are inconsistent and not standardized across hospitals. Many of the analyses cited by the authors in discussing hospital charges actually assessed cost-to-charge ratios $^{2-5}$ or episode payments ${ }^{6}$ rather than hospital charges, which is an important distinction. In Michigan, we have assessed hospital variation in episode payments, ${ }^{6-8}$ rather than hospital charges, cost-to-charge ratios, or other estimates of cost. Episode payments may be a better reflection of payers' and society's perspective on cost, since they reflect

\footnotetext{
From the Department of Cardiac Surgery, University of Michigan, Ann Arbor, Mich. Disclosures: The authors reported no conflicts of interest.

The Journal policy requires editors and reviewers to disclose conflicts of interest and to decline handling or reviewing manuscripts for which they may have a conflict of interest. The editors and reviewers of this article have no conflicts of interest.

Received for publication April 10, 2021; revisions received April 10, 2021; accepted for publication April 12, 2021; available ahead of print April 17, 2021.

Address for reprints: Gorav Ailawadi, MD, MBA, Department of Cardiac Surgery, University of Michigan School of Medicine, 1500 E. Medical Center Dr, SPC 5856, Ann Arbor, MI 48109 (E-mail: ailawadi@med.umich.edu).

J Thorac Cardiovasc Surg 2023;165:775-6

$0022-5223 / \$ 36.00$

Copyright (c) 2021 by The American Association for Thoracic Surgery

https://doi.org/10.1016/j.jtcvs.2021.04.033
}

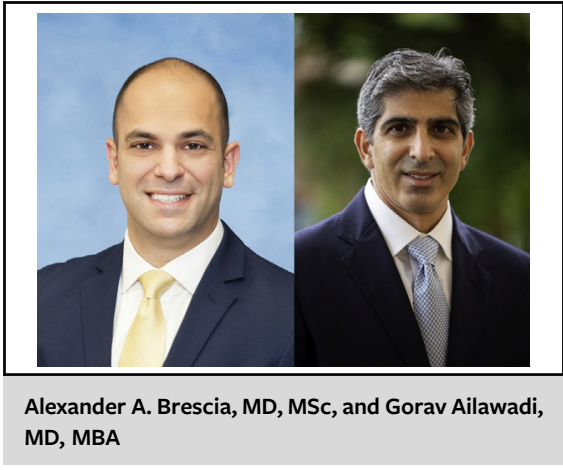

\author{
CENTRAL MESSAGE \\ Value is a measure of quality \\ versus cost and is an important \\ metric for CABG. Hospital \\ charges, though easy to capture, \\ do not accurately reflect cost. \\ True cost accounting is needed \\ in our specialty.
}

the actual realized cost of the episode of care rather than what is billed and may therefore be more relevant to bundled payments and value-based reimbursement. ${ }^{8}$

Minimizing spending/costs alone will not guarantee achieving high-value care without also delivering highquality care. Donabedian, ${ }^{9}$ the founder of the study of quality in health care, defined a hospital's performance as the byproduct of processes of care, outcomes, and a hospital's structure. Salenger and colleagues ${ }^{1}$ assessed quality with postoperative outcomes from Maryland STS ACSD, while notably concluding that patient risk profile as described through STS Predicted Risk of Mortality only accounted for $10 \%$ of the statistical variance in charges across hospitals. Among all hospitals in the national STS ACSD, we similarly found that only $2 \%$ of hospital variation in postCABG pneumonia rates are explained through traditional factors. ${ }^{10}$ Many consider "value" to be defined as quality divided by cost, which we estimated through risk-adjusted clinical outcomes and risk-adjusted, price-standardized 90-day episode payments, respectively. ${ }^{8}$ Specifically, we found significant variation among 33 Michigan hospitals performing $\mathrm{CABG}$ and, more importantly, identified specific targets to maximize value, including avoiding prolonged length of stay, prolonged intubation, and operative mortality while achieving lower spending, specifically in professional payments. ${ }^{8}$ Continuous quality improvement 
efforts through statewide collaboratives will need to address the hospital structure and processes of care components of quality. Assessing value using appropriate metrics for both quality and cost will be essential to evaluating cardiac surgical care in the era of value-based reimbursement.

In conclusion, the authors should be commended for describing sources of charge variation among hospitals, while true costs remain an enigma. Standardized cost accounting is needed at hospitals and in databases to identify targets to optimize performance in the setting of value-based care.

\section{References}

1. Salenger R, Etchill EW, Fonner CE, Alejo D, Matthew TL, Whitman GJR, et al. Hospital variability in modifiable factors driving coronary artery bypass charges. J Thorac Cardiovasc Surg. 2023;165:764-72.e2.

2. Kilic A, Shah AS, Conte JV, Mandal K, Baumgartner WA, Cameron DE, et al. Understanding variability in hospital-specific costs of coronary artery bypass grafting represents an opportunity for standardizing care and improving resource use. J Thorac Cardiovasc Surg. 2014;147:109-16.
3. Osnabrugge RL, Speir AM, Head SJ, Jones PG, Ailawadi G, Fonner CE, et al. Prediction of costs and length of stay in coronary artery bypass grafting. Ann Thorac Surg. 2014;98:1286-93.

4. Mehaffey JH, Hawkins RB, Byler M, Charles EJ, Fonner C, Kron I, et al. Cost of individual complications following coronary artery bypass grafting. J Thorac Cardiovasc Surg. 2018;155:875-82.e1.

5. Rich JB, Fonner CE, Quader MA, Ailawadi G, Speir AM. Impact of regional collaboration on quality improvement and associated cost savings in coronary artery bypass grafting. Ann Thorac Surg. 2018;106:454-9.

6. Guduguntla V, Syrjamaki JD, Ellimoottil C, Miller DC, Prager RL, Norton EC, et al. Drivers of payment variation in 90-day coronary artery bypass grafting episodes. JAMA Surg. 2018;153:14-9.

7. Brescia AA, Syrjamaki JD, Regenbogen SE, Paone G, Pruitt AL, Shannon FL, et al. Transcatheter versus surgical aortic valve replacement episode payments and relationship to case volume. Ann Thorac Surg. 2018;106:1735-41.

8. Brescia AA, Vu JV, He C, Li J, Harrington SD, Thompson MP, et al; Michigan Society of Thoracic and Cardiovascular Surgeons Quality Collaborative and Michigan Value Collaborative. Determinants of value in coronary artery bypass grafting. Circ Cardiovasc Qual Outcomes. 2020;13:e006374.

9. Donabedian A. The quality of care: how can it be assessed? JAMA. 1988;260: 1743-8.

10. Brescia AA, Rankin JS, Cyr DD, Jacobs JP, Prager RL, Zhang M, et al; Michigan Society of Thoracic and Cardiovascular Surgeons Quality Collaborative. Determinants of variation in pneumonia rates after coronary artery bypass grafting. Ann Thorac Surg. 2018;105:513-20.
See Article page 764 .

\section{Commentary: Costs of coronary artery bypass grafting: We can do better}

Nicolas H. Pope, MD, and Arman Kilic, MD

Healthcare spending remains a hot topic among patients, healthcare providers, payers, and policy makers. As such, it behooves providers to take an active role in examining healthcare costs, in an effort to provide the best patient

From the Division of Cardiothoracic Surgery, Medical University of South Carolina, Charleston, SC.

Disclosures: Dr Kilic serves on the medical advisory board for Medtronic. Dr Pope reported no conflicts of interest.

The Journal policy requires editors and reviewers to disclose conflicts of interest and to decline handling or reviewing manuscripts for which they may have a conflict of interest. The editors and reviewers of this article have no conflicts of interest.

Received for publication April 12, 2021; revisions received April 12, 2021; accepted for publication April 13, 2021; available ahead of print April 20, 2021.

Address for reprints: Arman Kilic, MD, Medical University of South Carolina, 30 Courtenay Dr, Suite BM 279 MSC 295, Charleston, SC 29425 (E-mail: kilica@ musc.edu).

J Thorac Cardiovasc Surg 2023;165:776-7

$0022-5223 / \$ 36.00$

Copyright $₫ 2021$ Published by Elsevier Inc. on behalf of The American Association for Thoracic Surgery

https://doi.org/10.1016/j.jtcvs.2021.04.039
Check for updates

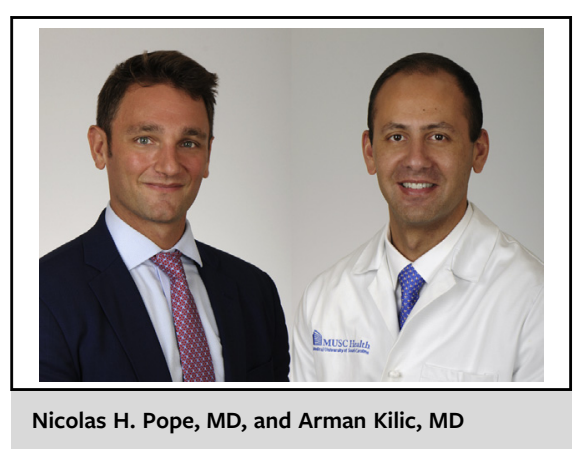

CENTRAL MESSAGE

Hospital charges varied widely in

a statewide retrospective review

of more than 7500 patients un-

dergoing coronary artery bypass

grafting. Importantly, only 10\%

of this variability was attributable

to patient risk profile.

care while controlling spending. Part of the difficulty in surveying healthcare spending is that hospital charges and actual cost are not interchangeable; however, these variables can be normalized such that charges can serve as a 